DOI: $\underline{\text { https://doi.org/10.24867/06GI06Mitrovic }}$

\title{
UPOTREBA TEHNOLOGIJE VIRTUELNE I PROŠIRENE STVARNOSTI U MARKETINGU
}

\section{THE USAGE OF VR AND AR TECHNOLOGY IN MARKETING}

\author{
Ksenija Mitrović, Fakultet tehničkih nauka, Novi Sad
}

\section{Oblast - INŽENJERSKI MENADŽMENT}

Kratak sadržaj - Cilj ovog istraživanja podrazumeva ispitivanje nivoa $i$ uspešnosti upotrebe virtuelne $i$ proširene stvarnosti u sklopu marketinških aktivnosti. U okviru teme dat je osvrt na izazove $i$ prihvatanje virtuelnih rě̌enja od strane potrošača. Na primeru brenda Ikea prikazana su tri sučaja primene VR-a i AR-a $i$ opisani njihovi ciljevi $i$ efekti. Istraživanje dobija na značaju u periodu kada Industrija 4.0 unosi revolucionarne promene na poslovnom polju i kada se kompanije susreću sa transformacijom u svoj digitalni oblik.

Ključne reči: Virtuelna stvarnost, Proširena stvarnost, Marketing

Abstract -The aim of this research is to examine the level and success of the usage of virtual and augmented reality in the context of marketing activities. Within the subject, challenges and consumer's acceptance of this emerging technology and it's virtual solutions are given also. Brand Ikea is used as an example with three different cases of the usage of $V R$ and $A R$, explaining their goals and effects. Research is relevant during a time when Industry 4.0 is revolutionizing the business field and companies are transforming into their digital form.

Keywords: Virtual Reality, Augmented Reality, Marketing

\section{UVOD}

Sa napretkom tehnologije i novim rešenjima svet je sve bliži situaciji u kojoj se ne razlikuje digitalno okruženje od realnog. Ovakve promene redefinišu savremene uslove poslovanja tako da se kompanije suočavaju sa izazovima prihvatanja digitalne transformacije i uvođenja iste $u$ svoju strategiju. Jedan potpuno novi sloj poslovnog okruženja koji nastaje daje velike mogućnosti marketinškoj funkciji, ali i poslovanju u celini. Kako bi se te mogućnosti iskoristile potreban je strategijski pristup digitalnim inovacijama i digitalnom razvoju, i unutar kompanije i u okruženju.

Marketing posmatra digitalne tehnologije kao priliku da usvajanjem inovacija ponudi novu vrednost potrošačima $i$ nove oblike komunikacije i interakcije. S obzirom na značaj marketing iskustva koji danas postaje fokus marketinških napora, VR i AR se pokazuju kao adekvatno rešenje da se jedinstveno iskustvo iznese.

\section{NAPOMENA:}

Ovaj rad proistekao je iz master rada čiji mentor je bio doc. dr Đorđe Ćelić.
Upotreba virtuelne i proširene stvarnosti prikazana je kroz tri primera: aplikacija sa ugrađenom proširenom stvarnošću IKEA Place, aplikacija za uvođenje u virtuelnu stvarnost IKEA VR Kitchen Experience i IKEA Virtual Experience doživljaj prikazan na otvaranju jednog objekta.

U rezultatu sve viših očekivanja kupaca korišćenje novih tehnologija generisanjem veštačkog okruženja u koje se kupac uvodi postaje adekvatan odgovor na promene uzrokovane Industrijom 4.0 nudeći kako hedonističku, tako i utilitarističku vrednost.

\section{DIGITALNE TEHNOLOGIJE ZA DIGITALNE POTROŠAČE}

Savremeno poslovno okruženje karakterišu povezanost, brzina i neopipljivost. U takav sklop odlika uklapa se digitalna transformacija i nove tehnologije koje je pokreću, a posebno VR i AR. Digitalna transformacija podrazumeva unapređenje ili reorganizaciju procesa korišćenjem svih raspoloživih digitalnih alata $i$ tehnologija [1]. Industrijski procesi više ne mogu da dopuste sebi da se zasnivaju na zastarelim i zatvorenim sistemima. Korisnici očekuju drugačiju komunikaciju sa kompanijama, zasnovanu na modernim osnovama.

Marketing u digitalnim tehnologijama vidi dobru šansu i alat da unese novine u svoje aktivnosti i način poslovanja. One unapređuju performanse, dovode do rasta prodaje $\mathrm{i}$ produktivnosti, do inovacija pri stvaranju vrednosti za potrošače i uvode nove oblike komunikacije i intreakcije sa kupcima. Nije lako udvoljiti novim onlajn kupcima koji imaju moć da neprestano redefinišu iskustvo kupovine koje žele da imaju. Naročito ne danas, u svetu koji je konstantno „uključen“, koji zahteva digitalni sadržaj, digitalne opcije i dostupnost tokom 24 časa.

Kao odgovor na uslove nametnute novom generacijom kupaca koji su odrasli uz digitalnu tehnologiju, u svet digitalne prodaje i marketinga uvode se novi alati, a uspešnu primenu ostvaruju i virtuelna i proširena stvarnost.

Zahvaljujući usvajanju pametnih telefona i ekspanziji interneta, javlja se uzbudljiva prilika za marketing stručnjake koji primenom tehnologije VR i AR pokušavaju da ožive etikete, izloge, kataloge na potpuno nov način i tako dođu do novih kupaca, posebno digitalnih, na koje tradicionalne marketinške aktivnosti više ne deluju. 


\subsection{Ekonomija iskustva}

Brendovi se danas suočavaju sa izazovom da kreiraju uspešnu promociju bez nužnog fokusiranja na promociju proizvoda ili usluge. Stalno izlaganje različitim porukama menja izgled strategija kampanje koja se okreće isticanjem iskustva, a ne proizvoda. Iskustvo se smatra ključnim elementom za stvaranje vrednosti u kompanijama. Iako nije novi fenomen, novijeg je datuma posmatranje njegovog koncepta kao poslovne prilike. Pojam ekonomija iskustva prvobitno je predstavljen $\mathrm{u}$ analizi društvenih slojeva koju je sastavio Schulze i u knjizi The Experience Economy koju su napisali Pine i Gilmore [2].

Ljudi postaju imuni na poruke koje im upućuju brendovi. Način da se dođe do kupaca danas ide preko iskustva. „Iskustvo je marketing“ postaje osnovna vodilja za kreiranje tražnje i stvaranje lojalnosti [3]. Potencijalni kupci uvode se $\mathrm{u}$ personalizovane prezentacije koje koriste nove tehnologije poput VR-a i AR-a kako bi demonstrirali primenu različitih proizvoda. Samo iskustvo shvaćeno kao lično relevantno i koje sadrži elemente novosti, iznenađenja i angažmana biće korisno za potrošače [4]. Oni očekuju da se zabave, edukuju i budu uključeni. Bilo da je rezultat podsticanje na razmišljanje ili sama kupovina, uspeh koji se postiže iskustvenim marketingom je značajan.

\subsection{Koncept i značaj virtuelne i proširene stvarnosti}

Poslovno okruženje kakvo postoji danas nameće uslove u kojima su interakcije posredovane i sve više vođene tehnologijama. Retki su poslovi koji ne sadrže elemente virtuelnog. Uzbudljiva nova tehnologija koja obećava transformaciju načina na koji ostvarujemo interakciju sa svetom sve se više usvaja i primenjuje. Virtuelna stvarnost transportuje čoveka na drugo mesto, u potpuno novo okruženje i to tako da on oseća da je stvarno prisutan i uroni u iskustvo drugačije realnosti. Čovek spoznaje svet oko sebe uz pomoć čula i sistema percepcije. Osnovna ideja je da se prevari sistem percepcije tako što se realni nadražaji koje primaju čula zamenjuju veštački generisanim nadražajima [5]. Uz pomoć računarskih sistema realno okruženje se modifikuje i pruža mogućnost interakcije i nekog vida istraživanja stvarajući tako virtuelnu stvarnost. Iako je prvobitno namenu našla $u$ industriji igara, VR tehnologija je svojim razvojem ušla u brojne industrije u različitim kapacitetima.

AR podrazumeva stvaran svet koji je proširen komjuterski generisanim podacima i objektima. Ova tehnologija dostavljajući digitalne transformacije širom sveta olakšava kompleksnim poslovnim sistemima da bolje funkcionišu. Uz pomoć odgovarajućih uređaja i algoritama $u$ prostor se dodaje nešto što ne postoji. Tako se javlja kombinacija realnog i virtuelnog sveta.

Proširenu stvarnost karakterišu jednostavnost, interaktivnost $\mathrm{i}$ atraktivan pristup. Nudi interaktivno iskustvo nadogradnjom realnog okruženja korisnika. AR aplikacije kreću se od onih jednostavnih kao što su tekstualna obaveštenja, do složenih poput uputstava pri izvođenju hirurškog zahvata.

Neke od prednosti AR-a prepoznate su od strane različitih kompanija [6]:
- Povećanje znanja i informacija;

- Međusobna razmena iskustva u realnom vremenu na velikim daljinama;

- Pojačano iskustvo stvarnosti atraktivno za korisnika. Navedene prednosti korišćene su i u marketingu što će biti prikazano na primeru brenda Ikea.

\section{UPOTREBA VIRTUELNE I PROŠIRENE STVARNOSTI U MARKETINGU}

Virtuelna i proširena stvarnost imaju stvarne i jake efekte na ljude i brendovi moraju da razmatraju njihovu primenu u okviru svojih kampanja. Tako je korisnicima omogućeno da vizualizuju $\mathrm{i}$ iskuse proizvode $\mathrm{i}$ usluge pre same kupovine. Onlajn kupovina postala je uobičajena i zaživela je pre nekoliko godina. Ograničnja poput nepoverenja su prevaziđena, ali neki i dalje biraju odlazak u prodavnicu jer su pristalice probavanja i detaljnog pregleda komada koji kupuju. AR i VR kombinuju praktičnost kupovine na mreži sa poverenjem koje daje vizuelizacija i mogućnost isprobavanja, kao da je potrošač posetio objekat.

Tako oni mogu da odaberu pravu nijansu, planiraju sledeću turističku destinaciju i pronađu odgovarajuću veličinu odevnih predmeta. Taj dodatni nivo poverenja pre kupovine koji pokazuje odabrane stvari na čoveku postaje koristan kako za njega tako i za oglašivače. Na primeru brenda Ikea biće prikazana uspešna upotreba VR-a i AR-a u marketinške svrhe kroz 3 primera.

\subsection{IKEA Place aplikacija}

IKEA place projekat zamišljen je tako da obezbedi benefite i potrošačima i kompaniji. Kreiranjem ovakvih inovativnih rešenja Ikea daje do znanja svojim kupcima da brine o njima $\mathrm{i}$ da radi na unapređenju njihove satisfakcije. Sve to dovodi do čvršće veze i lojalnosti koji se mogu posmatrati kao dugoročni cilj gotovo svakog marketinškog napora. Kada je u pitanju konkretno ARaplikacija koju je osmislila Ikea, polazilo se od pružanja podrške kupcima i utilitaristički aspekt imao je primat. Neki od ciljeva obuhvatali su:

- Eliminisanje grešaka pri kupovini;

- Osiguravanje rešenja koja su najprikladnija za individualne potrebe potrošača;

- Pružanje prijatnog i zabavnog iskustva pri rešavanju praktičnih problema;

- Podizanje svesti o brendu kao inovativnom i da mu je stalo do svojih kupaca.

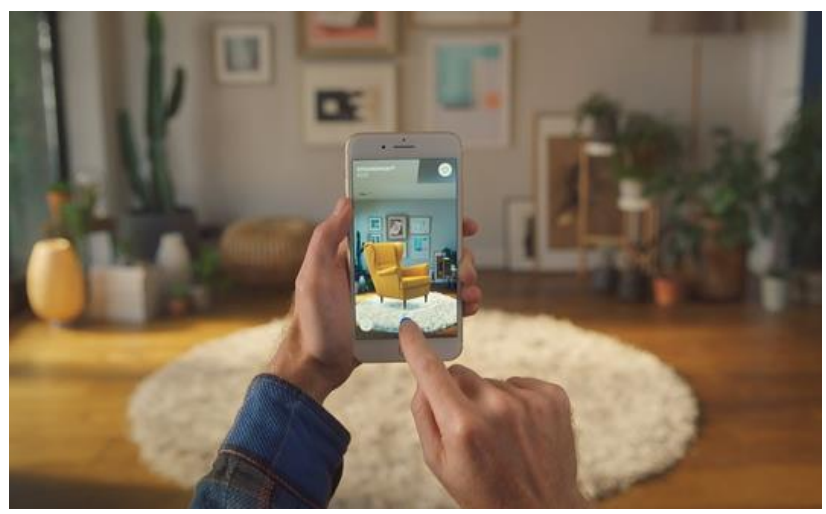

Slika 1: IKEA Place aplikacija [7] 
IKEA place aplikacija (slika 1) predstavljena je publici u septembru 2017. godine kada je švedska kompanija za nameštaj primenom proširene stvarnosti omogućila kupcima da lakše zamisle nameštaj u svom domu, kafiću ili kancelariji. Dimenzije su precizne, a 3D prikaz verno oslikava kako će se predmet ukopiti u prostor. Kupcima je teško da zamisle kako će se komad nameštaja prevesti iz izloga u realan prostor. Dimenzije i raspored često su problematični, s obzirom da je maloprodajni prostor takav da se predmeti čine manji nego što zapravo jesu.

Udruživanjem korisnog i zabavnog aspekta omogućene su različite prednosti:

1. Rast poverenja usled virtuelnog probanja pre kupovine

2. Pružanje edukativnog iskustva

3. Pružanje privlačnog iskustva

4. Minimiziranje povrata proizvoda

5. Rast angažovanosti kupaca

Aplikacija je prvobitno bila dostupna korisnicima iOS-a, a nekoliko meseci kasnije i korisnici Androida su mogli da je koriste. Ocene na platformama za preuzimanje se razlikuju, ali ukupan efekat je pozitivan. Korsinicima je aplikacija dala mogućnost da reše praktične problem prlikom donošenja odluke o kupovini, a pored toga ocenjuju je kao zabavnu.

\subsection{IKEA VR Kitchen Experience}

Preuzimanjem aplikacije sa platforme Steam i pokretanjem uz pomoću HTC Vive- $a$, potrošači mogu da istražuju kuhinje ovog brenda u virtuelnom okruženju. Pored kretanja kroz nju, mogu da se obavljaju jednostavni zadaci kako bi se došlo do idealne kuhinje (slika 2).

Jednostavnim klikom menja se boja ormara ili fioke, oni mogu da se otvaraju i pregledaju iz različitih perspektiva: sa $100 \mathrm{~cm}$, korisnikove visine i $195 \mathrm{~cm}$ [8]. Cilj ovakvog poduhvata je kreiranje zabavnog iskustva primenom tehnologije virtuelne stvarnosti. Aplikacija je usmerena na rekreaciju, relaksaciju i igru pre nego na funkcionalan aspekt.

Korišćenje VR tehnologije u marketinške svrhe može biti veoma skupo ukoliko se kreira za malu publiku. Međutim,Ikea je postavila okvir i postala prepoznatljiva po uvođenju novih tehnologija kako bi se unapredilo potrošačko iskustvo. Svaka aplikacija, igra, može ponovo da se koristi, a nošenje VR opreme postaje deo Ikeinog identiteta.

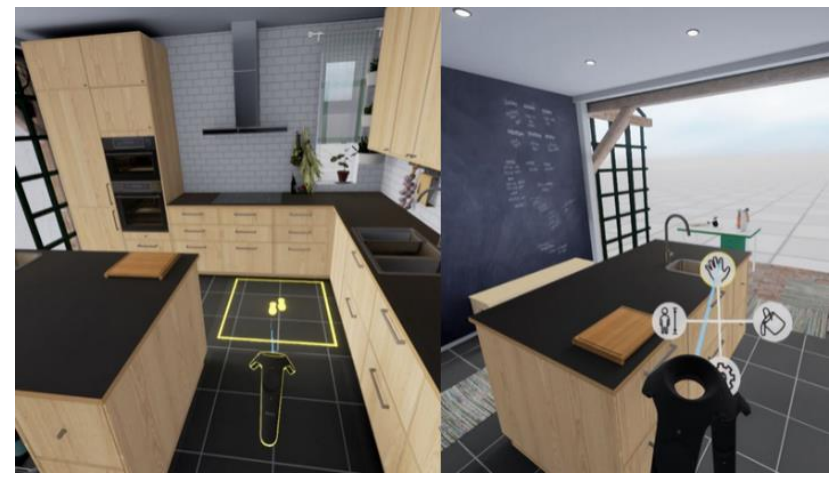

Slika 2: IKEA VR Kitchen Experience [9]
Potrošači su kroz ovaj projekat dobili značajniju ulogu: oni doprinose kreiranju i razvoju novih proizvoda i kombinacija kroz povratne informacije koje ostavljaju tokom svog VR iskustva.

$V R$ Kitchen Experience deluje kao komunikacijski proces između kupaca i brenda i i povezuje ih smanjujući jaz između njih.VR iskustvo navodi korisnike da vizualizuju različite kombinacije i budi njihovu kreativnost. Ovakav vid aplikacije pružanovi emocionalan doživljaj proizvoda i revolucionira način na koji se kupci uključuju u uređenje enterijera.

Predstavljanje novih stvari može da bude prilično rizično za kompanije. Upuštanje u iskustvo virtuelne stvarnosti nije probalo puno ljudi. Aplikacija koja odvodi korisnike u virtuelnu kuhinju može da naiđe na izazove prilikom promovisanja iskustva i stvaranje zainteresovanosti kod ljudi koji ne prihvataju novine i nisu skloni probanju novih stvari.

To se prvenstveno odnosi na starije generacije koje nisu tehnološki osvešćene. Postoje ljudi koji odbijaju da drže korak sa tehnološkim napretkom i da mu se prilagode. Tako deo potencijalnih korisnika možda nema uređaj na kom bi pokrenuo aplikaciju ili mu nedostaje tehnička pismenost.

Ukoliko aplikacija nije dostupna na više jezika i to može da bude značajna prepreka. „Tehnološka anksioznost“ nije izražena kod mlađih generacija koje su voljne da probaju i prihvate nove tehnologije. Međutim ona je izražena kod starijih ljudi koji imaju osećaj nelagodnosti kada se sustretnu sa tehnološkim rešenjima pred sobom i nisu sklone njihovom korišćenju.

Često se zahteva obuka prodajnih saradnika kako bi mogli da budu podrška korisnika pri isprobavanju novog iskustva. Nizak nivo stručnosti i posvećenosti zaposlenih kada je tehnologija u pitanju dodatno otežava ovu okolnost.

Potrebno je imati u vidu i mogućnost povrede, pada, gubitka ravnoteže. Ukoliko je iskustvo imerzivno, korisnik je potpuno izuzet od spoljnog sveta i može da izgubi osećaj za prostor.

\subsection{IKEA Virtual Experience - Otvaranje objekta u Dalasu}

Primena VR tehnologije imala je za cilj da upotpuni događaj kao što je otvaranje novog objekta. Posetiocima je pruženo neponovljivo iskustvo kako bi ih vratilo ponovo u prodavnicu i skrenulo njihovu pažnju na brend. Marketing stručnjaci osmislili su nekoliko imerzivnih doživljaja kako bi uspeli da pomoću kreiranih igara i demonstracija edukuju posetioce o održivosti i dizajnu svojih proizvoda, novoj grupi potencijalnih kupaca približe priču i vrednosti brenda.

Takođe, omogućeno je upoznavanje sa jedinstvenom imerzivnom instalacijom koja će Ikeu pozicionirati kao brend kom inovacije nisu strane, a cilj je bio i da se privučešto veći broj posetilaca na otvaranje objekta. 


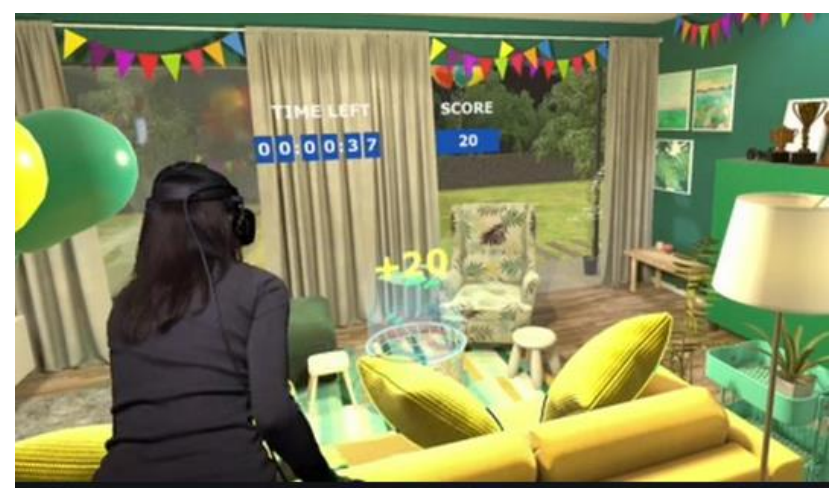

Slika 3:VR igra Pillow toss [10]

Razvojem iskustva virtuelne stvarnosti na HTC Vive-u korisnici su uvedeni mikro iskustva: "pillow toss" (slika 3) igru gde su imali zadatak da ubace što veći broj jastuka na zadato mesto, $\mathrm{u}$ šumu od bambusa ispunjenu pandama kako bi naučili nešto više o materijalu od kog se izrađuju lampe. Vođeni su i u svemir da bi im se pokazalo kako mogu da prilagode jedinice za odlaganje tako da imaju više prostora. VR iskustvo koje je kompanije predstavila povodom otvaranja objekta namenjen je onima koji nemaju uslove za primenu VR-a u svojim domovima.

$\mathrm{Uz}$ obezbeđenu opremu doživljaj je prezentovan onima koji vole odlazak u kupovinu ili je smatraju rutinom. Za ljude koji nisu okrenuti elektronskoj trgovini kreirano je digitalno iskustvo i sadržaj koji zabavlja, edukuje i relaksira tokom kupovine koja može biti stresna.

Ikea koristi virtuelnu stvarnost kako bi bolje istražila i zadovoljila potrebe svojih potrošača u digitalnom dobu. Za razliku od praktičnosti koju obezbeđuju AR rešenja, ovo je usmereno na zabavu i edukaciju. Nove tehnologije u ovom slučaju imaju zadatak da povežu realno i digitalno okruženje i pruže uzbudljivu aktivnost za angažovanje posetilaca u novom objektu.

Kupcu je data kontrola i izbegnut je autoritativni pristup gde kupci samo slušaju i gledaju. Kroz imerziju i interakciju efekat će biti jači jer dopire do kupca i ostaje u njegovoj memoriji.

Nedostupnost odgovarajuće opreme koju zahteva iskustvo virtuelne stvarnosti ovde je savladano time što se oprema nalazi u objektu i na raspolaganju je svima. Tako ljudi koji nisu bili u mogućnosti da vide Ikein virtuelni svet kod kuće, sada mogu to da učine u objektu.

\section{ZAKLJUČAK}

Efektna promocija bez nužnog isticanja proizvoda usmerava se na doživljaje koji nadražuju više ljudskih čula i više angažuje kupce. Virtuelna i proširena stvarnost raširene su u mnogim oblastima i olakšavaju poslovne alii druge probleme, a marketing je prepoznao njihovu moć u pružanju navedenih iskustava.
Iako je izgrađen brend, poznat širom sveta, kvalitet $\mathrm{i}$ renome nisu dovoljan garant za održavanje konkurentske prednosti. Svet se menja brže nego ikad i u takvim uslovima kompanije ne samo da moraju biti svesne promena, one moraju da budu ispred njih. Ikeaje usvojila nove načine povezivanja sa svojim kupcima i kroz nekoliko aplikacija, igara i virtuelnih rešenja pokazala uspešnu primenu VR-a i AR-a u marketingu.

\section{LITERATURA}

[1]M. Wade, „Digital business transformation“, Global Center for Digital Business Transformation, 2015.

[2] I. Vrhovski, „Ekonomija iskustva kao produkt kulturne globalizacije", Praktični menadžment, pp. 51-56. 2012.

[3] J. Pine, J. Gilmore, „The Experience is the Marketing “, BrownHerron Publishing, 2012.

[4] S. Poulsson, S. Kale, ,The Experience Economy and Commercial Experiences", The Marketing Review, pp. 267-277, 2004.

[5]R. Popović, D. Cvetković, D. Marković, „Multimedija“, Univerzitet Singidunum, 2010.

[6]S. R. Chavan, ,Augmented Reality vs. Virtual Reality: Differences and Similarities ", International Journal of Advanced Research in Computer Engineering \& Technology, pp. 1947-1952, 2016.

[7]https://www.ikea.com/au/en/apps/IKEAPlace.html (pristupljeno u septembru 2019.)

[8] https://www.ikea.com/ms/en_US/this-is-ikea/ikeahighlights/Virtual-reality/index.html (pristupljeno u septembru 2019.)

[9] https://www.vrheads.com/i-visited-ikea-vr-and-itblew-my-mind (pristupljeno u septembru 2019.)

[10] https://www.adweek.com/digital/ikea-is-steppinginto-virtual-reality-by-creating-a-game-for-new-storeopenings/(pristupljeno u septembru 2019.)

\section{Kratka biografija:}

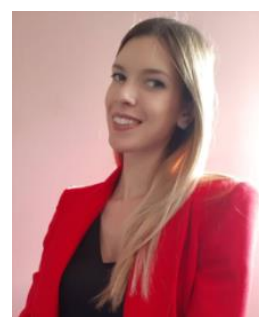

Ksenija Mitrović rođena je u Novom Sadu 1995. godine. Osnovne studije završila je na Ekonomskom fakultetu na smeru Marketing 2018. godine. Iste godine upisala je master studije na Fakultetu tehničkih nauka, smer Inženjerski menadžment. 